\title{
Effects of lingonberry extract (Vaccinium vitis-idaea L.) on the antioxidant, physicochemical and sensory characteristics of ice cream
}

\author{
Petya Boyanova ${ }^{1 *}$, Dilyana Gradinarska ${ }^{2}$, Valentina Dobreva ${ }^{3}$, Ivan Ivanov ${ }^{4}$, and Nadejda Petkova ${ }^{4}$ \\ ${ }^{1}$ Department of Milk and Dairy Products, Technological Faculty, University of Food Technologies, Plovdiv, Bulgaria \\ ${ }^{2}$ Department of Meat and Fish, Technological Faculty, University of Food Technologies, Plovdiv, Bulgaria \\ ${ }^{3}$ Department of Engineering Ecology, Economical Faculty, University of Food Technologies, Plovdiv, Bulgaria \\ ${ }^{4}$ Department of Organic Chemistry and Inorganic Chemistry, Technological Faculty, University of Food Technologies, Plovdiv, \\ Bulgaria
}

\begin{abstract}
In the present work, ice cream mixtures with 5\%,10\% and $15 \%$ lingonberry extract were studied. The lingonberry (Vaccinium vitis-idaea L.) is a source of anthocyanins and flavonoids, which are the bioactive components with good antioxidant properties. There was a significant increase in antioxidant activity $(\mathrm{p}<0.05)$ from $133.3 \pm 5.6 \mathrm{mM} \mathrm{TE} / 100 \mathrm{~g}$ to $249.8 \pm 8.3 \mathrm{mM} \mathrm{TE} / 100 \mathrm{~g}$ (ABTS method) with increasing the concentration of the extract from $5 \%$ to $15 \%$, respectively. Significant changes $(p<0.05)$ in the acidity and dry matter of the samples with lingonberry extract were recorded. After 30 days of storage, a decrease in the antioxidant properties $(\mathrm{p}<0.05)$ of the ice cream samples was observed but higher values $(\mathrm{mM} \mathrm{TE} / 100 \mathrm{~g})$ were maintained compared to the sample without extract. The color characteristics of the samples were also influenced by the concentration of the extract used. During storage, the highest stability of the colorimetric index a* (red component) was established, which indicates relative color stability during storage.
\end{abstract}

\section{Introduction}

In recent years, there has been a significant interest in the consumption of foods with increased biological and nutritional value. The new trend in the food industry requires the study of new plant sources of biologically active substances and natural pigments approved for use by the European Food Safety Authority (EFSA). Natural substances with pigment properties can be used as alternatives to synthetic colors, for which possible adverse effects have been reported [1].

Lingonberry (Vaccinium vitis-idaea L.), known as mountain cranberry or cowberry, is an evergreen shrub with edible fruits. Lingonberry (Vaccinium vitis-idaea) and cranberry (Vaccinium oxycoccus) are closely related and belong to the same family Ericaceae [2] but lingonberries are less studied as potential natural food ingredients than cranberries.

Due to their antioxidant effect, berry fruits have been defined as functional or so-called "super foods". Scientific research and articles report on the therapeutic and prophylactic benefits of berry fruit consumption $[3,4,5]$. According to studies on the antioxidant activity of various edible fruits (blueberries, cranberries, blackberries, strawberries, raspberries), lingonberries (Vaccinium vitisidaea L.) possess the most pronounced antioxidant properties [6]. This is mainly due to the abundant presence of cyanidin 3-galactoside in the anthocyanin content of lingonberries.
Anthocyanins are polyphenolic water-soluble natural colors. They are usually present in glycosidic form, i.e. associated with sugar residues of glucose, rhamnose, arabinose and galactose. Glycosylation increases the stability and water solubility of hydrophobic flavonoids (aglycones) $[7,8]$.

According to an evaluation by the EFSA Panel on Food Additives and Nutrient Sources based on the results of toxicological studies, anthocyanins (E 163) are approved for use as natural colorants in the European Union [9].

In the EFSA Journal, (2013), plant sources for anthocyanin extraction have not been specified, as no significant differences in their chemical composition are expected [9]. In Europe, anthocyanins are mainly isolated from edible fruits, such as grapes, apples, pears, and mostly from berries (Vaccinium spp.) [10]. The Joint FAO/WHO Expert Committee on Food Additives (JECFA) has established an acceptable daily intake of 2.5 $\mathrm{mg} / \mathrm{kg}$ of body weight for anthocyanins [7].

The proximate composition per $100 \mathrm{~g}$ of fresh berry fruit is represented by macronutrients: sugars $(4-5 \%)$, fibre $(2-4 \%)$, pectin $(1-4 \%)$, organic acids $(2.4 \%)$, and micronutrients: vitamins $\mathrm{C}, \mathrm{E}, \mathrm{K}, \mathrm{B}_{5}$; minerals $\mathrm{Cu}(0.08$ $\mathrm{mg}), \mathrm{Fe}(0.53 \mathrm{mg}), \mathrm{K}(40 \mathrm{mg})$ and $\mathrm{Ca}(10 \mathrm{mg})$ [11]. The content of biologically active and nutritious substances depends on various factors, such as climatic conditions, fruit maturity, soil composition $[3,5]$.

* Corresponding author: petyabboyanova@gmail.com 
According to literature data the main phenolic compounds in lingonberries are hydroxycinnamic acids, caffeic acid, vanillic acid and anthocyanins, as the latter are presented by three representatives as cyanidin-3galactoside, cyaniding-3-arabinoside and cyanidin-3glucoside [12,13].

The study of the chemical and functional properties of plant raw materials, as well as the technological possibilities to include natural ingredients in food, leads to an increase in the biological value and antioxidant activity of food.

The aim of the present study was to investigate the possibilities of incorporating lingonberry extract (Vaccinium vitis-idaea L.) in concentrations of 5\%, 10\% and $15 \%$ in ice cream mix. To achieve this goal, a comprehensive analysis of the changes in the antioxidant and color characteristics of ice cream samples during frozen storage was carried out. The physicochemical parameters and sensory perception of the ice cream samples were evaluated by a sensory panel.

\section{Material and Methods}

\subsection{Formulation of the ice cream samples}

Lingonberry extracts (Vaccinium vitis-idaea L.) were incorporated into ice cream mixtures to improve the color and antioxidant properties of the product. The extract was obtained from fresh lingonberry fruits (Vaccinium vitisidaea L.) from the region of Velingrad (Bulgaria). The fruits were cleaned and frozen at $-18^{\circ} \mathrm{C}$, then pressed with a filter cloth. The cold-pressed extract was used for supplementation of ice cream samples.

Fresh cow's milk (3.2\% fat), cream (37\% fat), sugar $(14 \%)$, gelatin $(0.5 \%)$ and raspberry flavor were used to prepare the ice cream mixture. After pasteurization at 85 ${ }^{\circ} \mathrm{C}$, the milk base was homogenized for $10 \mathrm{~min}$ and kept to mature at $6{ }^{\circ} \mathrm{C}$ for $17 \mathrm{~h}$. After cold maturation, the cranberry extract was incorporated at concentrations of $5 \%(\mathrm{C}-1), 10 \%(\mathrm{C}-2)$ and $15 \%(\mathrm{C}-3)$. Ice cream without lingonberry extract was used as a control sample $(\mathrm{C}-0)$. Preliminary experiments had shown that the use of the extract below 5\% leads to very weak coloring of the samples, and over $15 \%$ to a pronounced astringent taste (sour-bitter taste).

The samples of ice cream mix were freezed for $40 \mathrm{~min}$ in an ice cream machine Gelato Pro $2000,(250 \mathrm{~W}, 1.7 \mathrm{~L}$, Nemox, Italy). Samples of ice cream were placed in a freezer for hardening and storage. The samples were stored at $-18{ }^{\circ} \mathrm{C}$ for a month (30 days).

\subsection{Determination of biologically active substances and antioxidant activity of lingonberry extract and ice cream samples}

\subsubsection{Determination of total manometric anthocyanins content (TAC)}

Total anthocyanin content (TAC) was evaluated by measuring absorbance at $\lambda=510 \mathrm{~nm}$ and $\lambda=700 \mathrm{~nm}$. The results were calculated according to the $\mathrm{pH}$ differential method [14]. The results were expressed as mg cyanidin3-glycoside per $100 \mathrm{~g}$ sample.

\subsubsection{Extraction}

Ice cream samples $(\mathrm{C}-0, \mathrm{C}-1 ; \mathrm{C}-2, \mathrm{C}-3)$ and lingonberry extract were extracted with $80 \%$ methanol $(1: 5 \mathrm{w} / \mathrm{v})$ in an ultrasonic bath VWR (Malaysia) with frequency $45 \mathrm{kHz}$, power $30 \mathrm{~W}$ - (UAE $45 \mathrm{kHz}$ ) for $20 \mathrm{~min}$ at $35{ }^{\circ} \mathrm{C}$. The extraction was performed in triplicate. The extract was filtered and used for further analysis.

\subsubsection{Total phenolic content (TPC)}

The total phenolic content (TPC) was analyses according to the Folin - Ciocalteu method. In brief, $1 \mathrm{ml}$ of Folin Ciocalteu reagent (Sigma-Aldrich, Merck) was mixed with $0.2 \mathrm{ml}$ sample and $0.8 \mathrm{ml} 7.5 \% \mathrm{Na}_{2} \mathrm{CO}_{3}$ (SigmaAldrich, Merck). After $20 \mathrm{~min}$ the absorbance was measured by spectrophotometer at $\lambda=765 \mathrm{~nm}$. The results were expressed in $\mathrm{mg}$ of gallic acid equivalents (GAE) per $100 \mathrm{~g}$ dry weight (DW), using a calibration curve $\mathrm{y}=$ $12.557 \mathrm{x}-0.0871$, linear in the range of $0.02-0.10 \mathrm{mg}$ [15].

\subsubsection{Antioxidant activity}

ABTS + radical scavenging ability. The ABTS + solution $(2.85 \mathrm{ml})$ was mixed with $0.15 \mathrm{ml}$ extracts. The absorbance was measured at $734 \mathrm{~nm}$ against ethanol [15]. The results were shown as $\mathrm{mM}$ Trolox equivalents per $100 \mathrm{~g}$ dry matter (mM TE/100 g DM).

FRAP (Ferric Reducing Antioxidant Power) assay. The FRAP reagent was freshly prepared and consisted of $0.3 \mathrm{M}$ acetate buffer ( $\mathrm{pH} 3.6$ ), $10 \mathrm{mM}$ 2,4,6-tri(2-pyridyl)s-triazine (TPTZ) in $40 \mathrm{mM} \mathrm{HCl}$, and $20 \mathrm{mM}$ aqueous solution of $\mathrm{FeCl}_{3} \cdot 6 \mathrm{H}_{2} \mathrm{O}(10: 1: 1)$. FRAP reagent $(3.0 \mathrm{ml})$ was added to $0.1 \mathrm{ml}$ extract and after $10 \mathrm{~min}$, the absorbance was measured at $593 \mathrm{~nm} \mathrm{[15].} \mathrm{The} \mathrm{results}$ were expressed as mM Trolox equivalents per $100 \mathrm{~g}$ dry matter (mM TE/100 g DM).

\subsection{Physicochemical analysis of the ice cream samples}

The titratable acidity (TA) was determined by volumetric titrating. A sample of $5 \mathrm{~g}$ of ice cream diluted with $30 \mathrm{ml}$ of distilled water was titrated with $0.1 \mathrm{~N} \mathrm{NaOH}$ using an indicator of $1 \%$ phenolphthalein solution until a pale pink color appeared. In the case of colored ice cream (ice cream with cranberry extract), $5 \mathrm{~g}$ were diluted with $80 \mathrm{ml}$ of distilled water. The titratable acidity was expressed in Thörner degrees $\left({ }^{\circ} \mathrm{T}\right)$ and was calculated by the formula:

$$
\mathrm{TA}\left({ }^{\circ} \mathrm{T}\right)=\mathrm{V}_{\mathrm{NAOH}} \times 20
$$

The $\mathrm{pH}$ of melted ice cream samples was determined using a pH-meter (model InoLab pH 720, WTW GmbH, Germany), connected with $\mathrm{pH}$ combination electrode (SenTix 81, WTW GmbH, Germany). 
The total protein content was determined by the Kjeldahl method. A conversion factor of 6.38 was used to present the nitrogen content in protein concentration (\%).

The humidity (\%) was measured using a moisture analyser (model XM50, Kern, Germany) with a halogen heating system. $3 \mathrm{~g}$ of melted ice cream were dried at 102 $\pm 2^{\circ} \mathrm{C}$ to a constant weight.

The dry matter (DM) calculated according to the following formula:

$$
\text { Dry matter }(\%)=100-\text { Humidity }
$$

\subsection{Color characteristics}

The color was measured using a Minolta Chroma meter (model CR 410, Osakka, Japan) in the CIELab system. The evaluation was made using the $C$ illuminant and $2^{\circ}$ standard angle of observation. The positive and negative values of $a^{*}$ represents the red and green color, respectively. The positive and negative values of $b^{*}$ yellow and blue color. The lightness $\left(L^{*}\right)$ varies from black to white.

All measurements were performed five times in nonoverlapping zones.

\subsection{Sensory evaluation}

The sensory characteristics of ice cream samples were assessed by 15 panelists. The samples were tempered at $-15^{\circ} \mathrm{C}$ before analysis. The maximum scores of the assessed indicators (appearance, consistency, taste and flavor) are according to Bulgarian State Standard 395-85 (BSS 392-85) [16].

\subsection{Statistical analysis}

The values of the data presented in the tables are expressed as mean \pm standard deviation (SD). Data were subjected to one-way analysis of variance (ANOVA). A p
$<0.05$ value indicates significantly statistical difference. Statistical analysis was conducted using software product Statgraphics 18.0.

\section{Results and Discussion}

\subsection{Physicochemical characteristics}

The results of the physicochemical analysis of the control sample $(\mathrm{C}-0)$ and the samples of ice cream with concentrations of lingonberry extract of $5 \%(\mathrm{C}-1), 10 \%$ $(\mathrm{C}-2)$ and $15 \%(\mathrm{C}-3)$ are presented on Table 1.

Statistically significant changes $(p<0.05)$ in the values of acidity and dry matter of the ice cream samples were established. An increase in titratable acidity $\left({ }^{\circ} \mathrm{T}\right)$ from $17 \pm 0.1^{\circ} \mathrm{T}$ (control sample) to $50 \pm 0.1^{\circ} \mathrm{T}$ (sample with $15 \%$ extract) was measured. In terms of $\mathrm{pH}$, the increase in the concentration of the lingoberry extract resulted in a significant decrease in the $\mathrm{pH}$ values, which reached $4.6 \pm 0.01$ (sample with $15 \%$ extract). The increased acidity of the lingonberry ice cream samples could be explained by the measured low $\mathrm{pH}$ values of the extract added to the ice cream mixture $(\mathrm{pH}=3.43 \pm 0.02)$. The acidic nature of lingonberry extract is due to the presence of organic acids in their composition. According to literature data, the average chemical content of organic acids in lingonberry fruits is $2.4 \mathrm{~g} / 100 \mathrm{~g}$, of which 1.6 $\mathrm{mg} / 100 \mathrm{~g}$ is citric acid, $965 \mathrm{mg} / 100 \mathrm{~g}$ malic acid, and 312 $\mathrm{mg} / 100 \mathrm{~g}$ succinic acid [11]. There was a decrease in the dry matter values with increasing the lingonberry extract concentration - from $33.8 \pm 0.2 \%$ (control sample) to 26.3 $\pm 0.3 \%$ in the ice cream sample with $15 \%$ extract. The reason for the changes in the dry matter in the $\mathrm{C}-1, \mathrm{C}-2$ and $\mathrm{C}-3$ ice cream samples in comparison with the control sample $(\mathrm{C}-0)$ is the high moisture of the lingonberry extract $(88.5 \pm 0.3 \%)$. Average values of moisture of berries of about $86-90 \%$ have been reported in the literature [11].

Table 1. Physicochemical parameters of ice cream control sample and ice cream supplemented with lingonberry extract (concentrations 5\%,10\% and 15\%).

\begin{tabular}{|l|c|c|c|c|}
\hline \multirow{2}{*}{ Parameters } & \multicolumn{4}{|c|}{ Ice cream samples } \\
\cline { 2 - 5 } & $\mathrm{C}-0$ & $\mathrm{C}-1$ & $\mathrm{C}-2$ & $\mathrm{C}-3$ \\
\hline TA, ${ }^{\circ} \mathbf{T}$ & $17 \pm 0,1^{\mathrm{a}}$ & $24 \pm 0,1^{\mathrm{b}}$ & $35 \pm 0,2^{\mathrm{c}}$ & $50 \pm 0,1^{\mathrm{d}}$ \\
\hline pH & $6,7 \pm 0,01^{\mathrm{a}}$ & $5,7 \pm 0,02^{\mathrm{b}}$ & $5,3 \pm 0,01^{\mathrm{c}}$ & $4,6 \pm 0,01^{\mathrm{d}}$ \\
\hline Proteins, \% & $3,2 \pm 0,2^{\mathrm{a}}$ & $3,1 \pm 0,2^{\mathrm{a}}$ & $3,3 \pm 0,2^{\mathrm{a}}$ & $3,2 \pm 0,2^{\mathrm{a}}$ \\
\hline DM, \% & $33,8 \pm 0,2^{\mathrm{a}}$ & $30,9 \pm 0,1^{\mathrm{b}}$ & $28,3 \pm 0,2^{\mathrm{c}}$ & $26,3 \pm 0,3^{\mathrm{d}}$ \\
\hline
\end{tabular}

*TA-titratable acidity; DM-dry matter. The values of the table are expressed as mean \pm standard deviation (SD). The values followed by different superscript letters in the same row are statistically different $(\mathrm{p}<0,05)$.

\subsection{Biologically active antioxidant characteristics \\ substances and}

The total monomeric anthocyanin content (TAC) and total phenolic content (TPC) of the lingonberry (Vaccinium vitis-idaea $L$.) extracts and ice cream samples were determined by the $\mathrm{pH}$-differential method and Folin-
Ciocalteau method, respectively. Antioxidant properties were determined by ABTS (mM TE/100 g) and FRAP $(\mathrm{mM}$ TE/100 g) methods. The application of both methods allowed more complete characterization of the antioxidant properties of the test samples due to their different mechanisms of action - 2,2'-azino-bis (3- 
ethylbenzothiazoline6-sulphonic acid) radical scavenging activity (ABTS) and ferric reducing antioxidant power (FRAP).

The content of biologically active substances (phenolic compounds and anthocyanins) of the lingonberry extract and ice cream samples are presented in Table 2. The amount of TPC (mg GAE/100 g DM) and monometric anthocyanins (mg Cya-3 glc/100 g DM) of ice cream samples was measured on the $1^{\text {st }}$ and $30^{\text {th }}$ days of storage at $-18^{\circ} \mathrm{C}$.

For the cold-pressed extract (Vaccinium vitis-idaea L.), TPC of $652.8 \pm 5.4 \mathrm{mg} \mathrm{GAE} / 100 \mathrm{~g} \mathrm{DM}$ and $17.9 \mathrm{mg}$ \pm 0.4 Cya-3 glc/100 g DM were determined. The values obtained for TPC are similar to the contents reported by Dróżdż et al. [13] 468 - $661 \mathrm{mg}$ of GAE/100 g and significantly lower 26.1 - $43.0 \mathrm{mg}$ CGE/100 $\mathrm{g}$ for anthocyanins. The differences in the values of the TPCs (Folin method - Ciocalteu method) and anthocyanins, both in the raw fruit and in the lingonberry extract, can be explained by the different regions of cultivation, soil composition, temperature, relative humidity, different methods of processing of the raw material [11]. A significant part of the biologically active substances in fruits are in a bound state in the form of protein carbohydrate-phenolic complexes are found in the skin and cell wall of the raw material [11]. The disruption of the bonds in the complexes caused by the extraction method determines the amount of functional substances passed into the extract.

The TPC was measured to be in the range of $24.39 \pm$ $3.5 \mathrm{mg} \mathrm{GAE} / 100 \mathrm{~g}$ DM in the ice cream sample without lingonberry extract $(\mathrm{C}-0)$. According to recent studies $[18,19]$, cow's milk contains the polyphenolic compound equol, derived from daidzein, and found in plant sources used in animal feed. The biologically active phenolic compounds in the ice cream mixture originating from the milk base, explain the antioxidant activity determined in sample $\mathrm{C}-0$ by both methods (ABTS and FRAP) (Table $2)$. The incorporation of lingonberry extract led to a significant increase in the TPC $(\mathrm{p}<0.05)$ from $24.4 \pm 3.5$ $\mathrm{mg}$ GAE/100 g DM (sample C-0) to $38.40 \pm 3.9 \mathrm{mg}$ GAE/100 g DM (sample C-3) or presented as a percentage, this change is within $38-40 \%$.

In samples $\mathrm{C}-1, \mathrm{C}-2$ and $\mathrm{C}-3$, higher values of TPC (mg GAE/100 g DM) and TAC (mg Cya-3 glc/100 g DM) were measured with increasing the concentration of the extract from $5 \%$ to $15 \%$. However, the determined TPC was not statistically significant $(\mathrm{p}>0.05)$ for the samples with lingonberry extract (Table 2).

A statistically significant difference $(p<0.05)$ in the values of TAC was found between the ice cream samples with $5 \%(\mathrm{C}-1)$ and $15 \%$ extract $(\mathrm{C}-2)$. The results of the antioxidant activity determined by the ABTS and FRAP methods demonstrated an increase in the antioxidant properties with an increase in the concentration of the added extract (high content of TPC and TAC, respectively) (Table 2 ).

After 30 days of storage, a significant decrease $(\mathrm{p}<$ $0.05)$ in the content of biologically active substances was recorded (Table 2). In sample $\mathrm{C}-1$, the presence of TAC determined by spectrophotometric method was not detected after 30 days of storage.

Table 2. Changes in biologically active substances and antioxidant activity determined by ABTS and FRAP assays of ice cream samples during storage at $-18^{\circ} \mathrm{C}$.

\begin{tabular}{|c|c|c|c|c|}
\hline Sample & $\begin{array}{c}\text { TPC, } \\
\text { mg GAE } / 100 \text { g DM }\end{array}$ & $\begin{array}{c}\text { TAC, } \\
\text { mg Cya-3 glc } / 100 \mathrm{~g} \\
\text { DM }\end{array}$ & $\begin{array}{c}\text { ABTS, } \\
\mathrm{mM} \text { TE/100 g DM }\end{array}$ & $\begin{array}{c}\text { FRAP, } \\
\mathrm{mM} \text { TE/100 g DM }\end{array}$ \\
\hline Lingonberry extract & $652.8 \pm 5.4$ & $17.9 \pm 0.4$ & $2815.1 \pm 7.8$ & $1989.0 \pm 6.7$ \\
\hline \multicolumn{5}{|c|}{1 day of storage } \\
\hline $\mathrm{C}-\mathbf{0}$ & $24.4 \pm 3.5^{\mathrm{a}}$ & n.d & $76.6 \pm 7.2^{\mathrm{a}}$ & $17.3 \pm 7.4^{\mathrm{a}}$ \\
\hline $\mathrm{C}-1$ & $31.5 \pm 4.3^{\mathrm{a} . \mathrm{b}}$ & $1.2 \pm 0.2^{\mathrm{a}}$ & $133.3 \pm 5.6^{\mathrm{b}}$ & $60.2 \pm 8.5^{b}$ \\
\hline $\mathrm{C}-2$ & $36.4 \pm 4.6^{\mathrm{b}}$ & $2.9 \pm 0.5^{b}$ & $228.4 \pm 5.4^{\mathrm{c}}$ & $115.1 \pm 6.4^{\mathrm{c}}$ \\
\hline $\mathrm{C}-\mathbf{3}$ & $38.4 \pm 3.9^{b}$ & $3.2 \pm 0.3^{\mathrm{b}}$ & $249.8 \pm 8.3^{\mathrm{d}}$ & $143.6 \pm 7.2^{\mathrm{d}}$ \\
\hline \multicolumn{5}{|c|}{30 days of storage } \\
\hline $\mathrm{C}-1$ & $11.5 \pm 4.3^{\mathrm{a}}$ & n.d & $100.5 \pm 2.1^{\mathrm{a}}$ & $40.7 \pm 5.1^{\mathrm{a}}$ \\
\hline $\mathrm{C}-2$ & $14.4 \pm 3.4^{\mathrm{a}}$ & $0.2 \pm 0.2^{\mathrm{a}}$ & $113.1 \pm 5.9^{\mathrm{b}}$ & $64.3 \pm 4.2^{\mathrm{b}}$ \\
\hline $\mathrm{C}-\mathbf{3}$ & $25.6 \pm 5.5^{\mathrm{b}}$ & $0.4 \pm 0.3^{b}$ & $113.9 \pm 5.1^{\mathrm{b}}$ & $124.6 \pm 7.3^{\mathrm{c}}$ \\
\hline
\end{tabular}

*The values are expressed as mean \pm standard deviation (SD). The values followed by different superscript letters in the same rows are statistically different $(\mathrm{p}<0.05)$. The following letter designations are used: $a, b, c, d-$ in relation to the cranberry extract concentration. n.d. - not determined.

Ice cream samples $\mathrm{C}-2$ and $\mathrm{C}-3$ showed insignificant antioxidant properties $(p>0.05)$ defined by the ABTS method, while the values by the FRAP method were statistically different between the samples with berry extract.

The decrease in antioxidant activity is connected with the content of phenolic compounds and anthocyanins [20]. There are several factors that affect the degradation of phenolic compounds and anthocyanins, namely light, oxidation, unstable freezing temperature. The oxidation and $\mathrm{pH}$ of the food matrix are very important factors for the chemical stability of anthocyanins. Oxygen affects the degree of decomposition of anthocyanins, accompanied by partial opening of their ring structure [21].

\subsection{Color characteristics}

The values of the colorimetric parameters $\left(L^{*}, a^{*}, b^{*}\right)$ of the lingonberry ice cream samples on the $1^{\text {st }}$ day of storage at $-18^{\circ} \mathrm{C}$ are presented in Table 3 . The results obtained on 
the $1^{\text {st }}$ day of storage correspond to the changes of $L^{*}, a^{*}$, $b^{*}$ reported for ice cream enriched with plant sources containing anthocyanins $[17,22]$.

Lightness $\left(L^{*}\right)$ decreased with increasing the concentration of the added extract, and in all three samples a statistically significant difference $(\mathrm{p}<0.05)$ was found in the values of this colorimetric indicator. Higher values of the red component $a^{*}$ (positive sign) and lower values of the yellow component $b *$ (positive sign) were measured as the concentration of the incorporated lingonberry extract increased. The increase in the $a^{*}$ from $3.4 \pm 0.3(5 \%$ extract) to $19.2 \pm 0.8(15 \%$ extract $)$ was associated with the higher TAC in the samples (Table 2).

Table 3. Change in color parameters of ice cream samples supplemented with lingonberry extract during frozen storage.

\begin{tabular}{|c|c|c|c|}
\hline $\begin{array}{c}\text { Ice cream } \\
\text { samples }\end{array}$ & $\boldsymbol{L}^{*}$ & $\boldsymbol{a}^{*}$ & $\boldsymbol{b}^{*}$ \\
\hline \multicolumn{4}{|c|}{$\mathbf{1}^{\text {st }}$ day of storage } \\
\hline $\mathbf{C}-\mathbf{1}$ & $84.3 \pm 0.7^{\text {ax }}$ & $3.4 \pm 0.3^{\text {ax }}$ & $8.3 \pm 0.1^{\text {ax }}$ \\
\hline $\mathbf{C}-\mathbf{2}$ & $86.4 \pm 0.2^{\text {bx }}$ & $10.6 \pm 0.4^{\text {by }}$ & $3.7 \pm 0.1^{\text {bx }}$ \\
\hline $\mathbf{C}-\mathbf{3}$ & $75.0 \pm 1.1^{\text {cx }}$ & $19.2 \pm 0.8^{\text {cx }}$ & $1.9 \pm 0.2^{\text {cx }}$ \\
\hline \multicolumn{4}{|c|}{$\mathbf{3 0}^{\text {th }}$ day of storage } \\
\hline $\mathbf{C}-\mathbf{1}$ & $92 . \pm 4.1^{\text {ay }}$ & $3.2 \pm 0.1^{\text {ax }}$ & $10.8 \pm 0.4^{\text {ay }}$ \\
\hline $\mathbf{C}-\mathbf{2}$ & $86 . \pm 1.5^{\text {bx }}$ & $6.4 \pm 0.1^{\text {bx }}$ & $5.3 \pm 0.5^{\text {by }}$ \\
\hline $\mathbf{C}-\mathbf{3}$ & $81.6 \pm 3.0^{\text {by }}$ & $18.2 \pm 0.6^{\text {cx }}$ & $3.3 \pm 0.3^{\text {cy }}$ \\
\hline
\end{tabular}

*The values of the data are expressed as mean \pm standard deviation (SD). The values followed by different superscript letters in the same column are statistically different $(p<0.05)$. The following letter designations are used: $\mathrm{x}, \mathrm{y}, \mathrm{z}$ in relation to the time of storage, and $a, b, c-$ in relation to the cranberry extract concentration.

Depending on the $\mathrm{pH}$, anthocyanins exist in different forms, each of which determines a different color. At $\mathrm{pH}$ between 4 and 6 , four structural forms of anthocyanins are found: two colorless forms (carbinol base and anhydrous quinoidal base), chalcone and flavylium cation, which is responsible for the red through purple color. As the $\mathrm{pH}$ increases, the amount of bright yellow-colored chalcone increases and the amount of flavylium cation decreases [23]. The color changes in the samples corresponded to the measured $\mathrm{pH}$ values of the lingonberry ice creams (Table 1) and the associated structural changes in the anthocyanins. Despite the decrease in TAC during storage (Table 2), insignificant changes $(\mathrm{p}>0.05)$ were observed in the red component $a^{*}$, but significant in lightness $\left(L^{*}\right)$ and the yellow component $b^{*}$. These changes during storage can be explained by the processes of decomposition and oxidation of anthocyanins. It is known that their colorimetric characteristics depend not only on the pigment structure and concentration, but also on the $\mathrm{pH}$, temperature, the presence of sugars and oxidants [23].

\subsection{Sensory evaluation}

The results obtained from the sensory analysis of the ice cream samples show that the addition of lingonberry extract has a significant effect on the color and taste characteristics (Fig. 1). The addition of the extract to the mixture led to lower scores for the sensory attributes structure and consistency of the ice cream, which is associated with higher water content and crystal formation in these samples. However, in terms of color and fresh taste, there was a preference for the sample with $5 \%$ lingonberry extract.
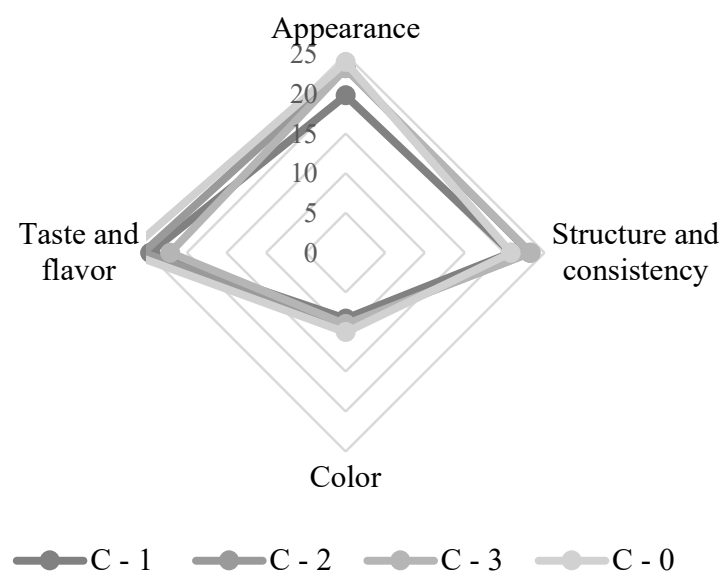

Fig. 1. Sensory evaluation of ice cream samples.

\section{Conclusions}

The lingonberry extract (Vaccinium vitis-idaea L.) in concentrations of $5 \%, 10 \%$ and $15 \%$ in ice cream leads to changes in the physicochemical and sensory properties, which are more pronounced with an increase in the concentration above $5 \%$.

From a sensory point of view, the use of crude lingonberry extract in the ice cream mixture is limited by the acid flavor characteristics of the ice cream. Despite the significant antioxidant activity determined in the ice creams supplemented with the lingonberry extract, after 30 days of storage the content of anthocyanins and phenolic compounds decreased more than twice, but without adversely affecting the color of the ice creams.

Further research is needed to define the optimal storage period in order to achieve the desired antioxidant effect and sensory perception of the innovative functional ice cream with lingonberry extract.

Acknowledgements: The present research was financially supported by the Science Fund at the University of Food Technology - Plovdiv, Bulgaria (Project 01/20 - H).

\section{References}

1. I.L.D. Moutinho, L.C. Bertges, R.V.C. Assis, Braz. J. Biol. 67, 141-145 (2007).

2. K. Kowalska, Int. J. Mol. Sci. 10, 5126 (2021)

3. J. Schell, N.M. Betts, M. Foster, R.H. Scofield, A. Basu, Food Func. 8, 3083-3090 (2017)

4. A.S. Kivimäki, A. Siltari, P.I. Ehlers, R. Korpela, H. Vapaatalo, J. Funct. Foods. 7, 238-245 (2014)

5. G.J. McDougall, H.A. Ross, M. Ikeji, D. Stewart, J. Agric. Food Chem. 56, 3016-3023 (2008) 
6. W. Zheng, S.Y. Wang, J. Agric. Food Chem. 51, 502509 (2003)

7. D. Bars-Cortina, A. Sakhawat, C. Piñol-Felis, M.J. Motilva, Semin. Cancer Biol. (to be published)

8. A.N. Winter, P.C. Bickford, Antioxidants. 8, 333 (2019)

9. EFSA Panel on Food Additives and Nutrient Sources added to Food (ANS), EFSA J. 11, 3145 (2013)

10. A. Kozłowska, T. Dzierżanowski, Molecules. 26, 4380 (2021)

11. G. Khomych, Y. Matsuk, J. Nakonechnaya, N. Oliynyk, L. Medved, East.-Eur. J. Enterp. Technol. 6, 59-65 (2017)

12. R. Apak, K. Güçlü, M. Ozyürek, S.E. Karademir, M. Altun, Free Radic. Res. 39, 949-961 (2005)

13. P. Dróżdż, V. Šèžienè, J. Wójcik, K. Pyrzyńska, Molecules. 23, 53 (2018)

14. J. Lee, R.W. Durst, R.E. Wrolstad, J. AOAC Int. 88, 1269 (2005)

15. I. Ivanov, R. Vrancheva, A. Marchev, N. Petkova Y. Aneva, P. Denev, G. Georgiev, I. Pavlov, Int. J. Curr. Microbiol. App. Sci. 3, 296 (2014)

16. Bulgarian State Standard 392: 1985 Ice-cream. General requirements (BIS, Sofia, 1985)

17. L. Hiranrangsee, K.K. Kumaree, M.B. Sadiq, A.K. Anal, J. Food Sci. Technol. 53, 3806-3813 (2016)

18. E.A Mustonen, M. Tuori, I. Saastamoinen, J. Taponen, K. Wähälä, H. Saloniemi, A. Vanhatalo, Br. J. Nutr. 102, 1552-1556 (2009)

19. S.Y. Tsen, J. Siew, E.K.L., Dairy Sci. Technol. 94, 625-632 (2014)

20. A.S. Baba, S. Amirdivani, Food Sci. Technol. 44, 1458-1464 (2011)

21. A. Castañeda-Ovando, M. Pacheco-Hernández, M.E. Páez-Hernández, J.A. Rodríguez, C.A. Galán-Vidal, Food Chem. 113, 859-871 (2009)

22. J.Y. Hwang, Y.S. Shyu, C.K. Hsu, LWT - Food Sci. Technol. 42, 312-318, (2009)

23. V. Zhivkova, Manag. Educ. 8, 11-15, (2012) 